\title{
Supporting Upper Elementary Students' Engineering Practices in an Integrated Science and Engineering Unit (Fundamental, Diversity)
}

\author{
Miss Sarah Lilly, University of Virginia
}

Sarah Lilly is a PhD student in the Department of Curriculum, Instruction and Special Education at the University of Virginia. She holds a B.S. in Mathematics and English and an M.A.Ed. in Secondary Education from The College of William and Mary. Her research centers on STEM education, particularly using qualitative methods to understand the integration of math and science concepts with computational modeling and engineering design practices in technology-enhanced learning environments. Prior to beginning doctoral work, she taught secondary mathematics for four years as well as created and implemented an interdisciplinary, project-based mathematics, science, and principles-of-technology curriculum for freshmen and sophomore high school students in Albemarle County, Virginia.

\section{Ms. Anne Marguerite McAlister, University of Virginia}

Anne McAlister is a PhD student in the Department of Curriculum, Instruction and Special Education in the Curry School of Education at the University of Virginia. She holds a BS in Chemical Engineering from The Ohio State University. Her research centers on engineering education, focusing on identity development in higher education.

\section{Dr. Sarah J Fick, University of Virginia}

Sarah Fick, PhD is a professor in the department of Curriculum, Instruction, and Special Education at Curry School of Education at the University of Virginia. She holds a BA in Biology and Environmental Studies from Bowdoin College, an MA in Science Education, an MS in Environmental Informatics, and a $\mathrm{PhD}$ in Science Education, all from the University of Michigan. Her research focuses on using qualitative methods to understand the intersection of teaching and learning in science education. She specifically focuses on the teaching practices needed to support students' to develop knowledge of the content, practices, and analytical lenses used to develop science knowledge.

\section{Dr. Jennifer L Chiu, University of Virginia}

Jennifer Chiu is an Associate Professor of STEM Education at the University of Virginia School of Education and Human Development. She holds a B.S. in Engineering (Product Design) from Stanford University and an M.A. and Ph.D. in Science Education from UC Berkeley. She researches how to support K-12 students, teachers, and preservice teachers across science, engineering, mathematics, and computer science disciplines as well as how to support STEM in informal learning contexts. Before becoming a professor, she worked as an engineer at Hewlett Packard and taught high school mathematics and science in California and Oklahoma.

\section{Dr. Kevin W McElhaney, Digital Promise}

Kevin McElhaney is Senior Research Scientist in STEM \& CS Education with the Learning Sciences Research group at Digital Promise. He holds a B.S. in Materials Science and Engineering from Stanford University, an M.S. in Materials Science and Engineering from Northwestern University, an Ed.M. in Teaching and Curriculum from Harvard University, and a Ph.D. in Science Education from UC Berkeley. He conducts design and implementation research on K-12 teaching, curriculum, and assessment across the science, engineering, and computer science disciplines. Previously, he conducted research on electronic materials at Intel Corporation and taught high school mathematics and science in California and Missouri. 


\title{
Supporting Upper Elementary Students' Engineering Practices in an Integrated Science and Engineering Unit
}

(Fundamental, Diversity)

\begin{abstract}
To support teachers in providing all students with opportunities to engage in engineering learning activities, research must examine the ways that elementary teachers support how diverse learners engage with engineering ideas and practices. This study focuses on two teachers' verbal supports in classroom discussions across two class sections of a four-week, NGSS-aligned unit that challenged students to redesign their school to reduce water runoff. We examine the research question: How and to what extent do upper-elementary teachers verbally support students' engagement with engineering practices across diverse classroom contexts in an NGSS-aligned integrated science unit? Classroom audio data was collected daily and coded to analyze support through different purposes of teacher talk. Results reveal the purpose of teachers' talk often varied between the class sections depending on the instructional activity and indicate that teachers utilized a variety of supports toward students' engagement in different engineering practices. In one class, with a large percentage of students with individualized educational plans, teachers provided more epistemic talk about the engineering practices to contextualize the particular activities. For the other class, with a large percentage of students in advanced mathematics, teachers provided more opportunities for students to engage in discussion and support for students to do engineering. This difference in supports may decrease the opportunities for some students to rigorously engage in engineering ideas and practices. This study can inform future research on the kinds of educative supports needed to guide teaching of integrated engineering activities for diverse students.
\end{abstract}

\section{Introduction}

The Next Generation Science Standards (NGSS) include engineering design practices and engineering concepts as part of what it means to do science at K-12 levels (National Research Council, 2012). Instead of a body of knowledge to be learned, the NGSS calls for students to be engaged in engineering practices such as defining problems, developing and using models, and designing solutions. Engineering practices work together with disciplinary core ideas (DCIs) and crosscutting concepts (CCCs) to engender a practice-based classroom where students engage, not only in the investigation of the world around them, but also in the application of scientific ideas to develop solutions that address human wants and needs (engineering).

Recent research efforts have focused on understanding how precollege teachers support students to engage in engineering practices (Watkins et al., 2018). Elementary school contexts can be particularly important as early exposure and experiences can have a lasting impact on students' identity development and subsequent interest in STEM courses and careers (Morgan et al., 2016). Yet elementary teachers often have little preparation or background to teach engineering and need support to be able to integrate engineering design into elementary science classroom settings. Thus, research must examine the ways that elementary teachers verbally support engineering practices. This paper explores how elementary teachers verbally support students' engagement in engineering practices in an NGSS-aligned unit. In particular, this paper compares the same teachers implementing the same curriculum across two class sections with different 
student populations. By exploring teacher talk across two different student contexts, we aim to help the field understand how teacher talk can support diverse students to engage in engineering practices.

\section{Background}

Classrooms can be viewed as learning communities where students construct knowledge by engaging in the practices of a domain (e.g., Lave \& Wenger, 1991). For students to engage in engineering, they need opportunities to participate in authentic engineering practices such as defining problems, planning and conducting investigations, as well as generating, testing, evaluating, refining, and communicating designs (Crismond \& Adams, 2012). As students participate in the learning communities of their classrooms, they learn the ways of thinking and reasoning inherent to engineering.

Helping students to engage in engineering practices can involve using instructional supports that break down complex practices into more manageable pieces for students (e.g., Reiser \& Tabak, 2014; Songer, 2006). One way to support students' engagement is through the use of curricular scaffolds embedded within instructional materials. However, curricular scaffolds are often static, not specific enough or adaptable enough to meet the needs of a wide range of students within a single classroom.

Teacher talk is a crucial component of engaging students in a learning community (Moje, 1995), and a productive way to employ such support for classroom activities for a diverse range of students (Songer, Shah, \& Fick, 2013). Teacher talk can change the complexity of the curricular task to make it accessible for certain students by giving examples of what a response might look like, or by framing the response with sentence starters or specific options to support sensemaking. Teacher talk can support students to use academic language, sequence tasks, breakdown challenging tasks into manageable pieces, highlight key ideas, or make connections to students' everyday lives (Krajcik et al., 2000; Songer, Shah, \& Fick, 2013).

In particular, teacher talk can help students engage in engineering practices. For example, research demonstrates that many precollege students have difficulty defining problems (e.g., Atman et al., 2007). Teacher talk can support students by asking questions about criteria and constraints or underscoring key client needs. Research also suggests that precollege students may have difficulty coming up with a wide range of potential designs (Luo, 2015). Teacher talk can help students generate designs by challenging them to change a particular aspect of a design or encouraging them to think about similar or different scenarios. Studies demonstrate that students need support to make informed revisions based on the testing of their designs (Wendell \& Lee, 2010). Teachers can also support students to test and evaluate their designs by drawing students' attention back to project criteria, or helping students to conduct fair tests of their designs. This kind of practical support can help students know how and why to engage in the engineering practices.

In addition to engineering practices, teacher talk can also support students to understand the nature of engineering and engineering thinking (Moore et al., 2014). For example, teachers can make explicit connections to the engineering profession to help students see themselves as 
engineers (Capobianco et al., 2011) and also help students develop more accurate conceptions of engineering (Ganesh \& Schnittka, 2014). Teachers can help students situate specific activities or tasks within the larger context of the project or the engineering endeavor. This kind of epistemic support can influence students' views of who can be engineers (Pantoya, Aguirre-Munoz, \& Hunt, 2015), potentially lead to improved learning outcomes (Lindsay et al., 2008), and help students persist in engineering courses (Arastoopour et al., 2014).

Despite the importance of teacher talk on student engagement in engineering, relatively little research has examined the ways that teachers modify their support in the moment to meet the needs of individual students (e.g., Aranda et al., 2018). In particular, very little research has examined how teachers may or may not give different kinds of supports to students with different academic backgrounds. For example, a teacher could anticipate that certain students might have difficulties with particular activities and proactively provide questions or guidance aimed to support the students' engagement with specific practices. In contrast, a teacher could anticipate that other students might not have difficulties and instead react to student needs in the moment. Because of the potential effect of teacher talk on the development of students' conceptions of who can and should be engineers, it is especially important to examine teacher talk across different groups of students.

Research studies have examined the impacts and affordances of epistemic vs. practical supports in various instructional contexts. We hypothesize that these types of supports have potential to improve student engagement with ideas and practices in K-12 engineering, but may not be equitably implemented in instruction. But this has not been adequately studied. Specifically, this study addresses the research question: How and to what extent do upper-elementary teachers verbally support students' engagement with engineering practices for different student groups in an NGSS-aligned engineering unit?

\section{Context and participants}

This study took place at a public elementary school in a southeastern state. Within the school district, 51 different languages are spoken by $14 \%$ of students, $51 \%$ of students in the district belong to underrepresented cultural groups in STEM, and 44\% qualify for free or reduced lunch. Two teachers co-taught two fifth grade class sections, the Orange Class and the Blue Class, following an NGSS-aligned project curriculum. Both teachers hold undergraduate degrees in a science field. A large proportion of students in the Orange Class were also in accelerated mathematics classes, while the Blue Class had a larger proportion of students with individualized educational plans (IEPs).

\section{Curriculum}

The four-week Water Runoff project had students redesign their school grounds, challenging them to reduce water runoff while addressing design criteria such as parking, grassy fields, and accessible play areas (Chiu et al., 2019). This study focuses particularly on three of the unit's engineering-focused lessons (Table 1). 
Table 1. Water Runoff activities and targeted NGSS practices for selected lessons in this study.

\begin{tabular}{lll}
\hline Lesson Name & Focal Engineering Practices & \multicolumn{1}{c}{ Activity Description } \\
\hline Design & Generating Designs & $\begin{array}{c}\text { Generate different playground designs given } \\
\text { data on different surface materials. }\end{array}$ \\
Test & $\begin{array}{l}\text { Test, Evaluate, and Refine } \\
\text { Designs }\end{array}$ & $\begin{array}{c}\text { Test different designs with computer models } \\
\text { to see which ones perform best and create } \\
\text { new solutions as needed. }\end{array}$ \\
& $\begin{array}{l}\text { Refine and Communicate } \\
\text { Communicate }\end{array}$ & $\begin{array}{c}\text { Refine designs with data from computer } \\
\text { models and prepare to present their } \\
\text { designs to the class. }\end{array}$ \\
\hline
\end{tabular}

\section{Data sources and analysis}

In order to examine how and to what extent teachers verbally supported students' engagement with engineering practices across different student groups, we coded teachers' talk during engineering-focused lessons. This involved identifying if statements made by the teacher (1) supported students, (2) supported students to engage in engineering practices, and (3) supported students to engage in engineering practices epistemically and/or practically.

This study used audio video recordings of whole class discussions during which the teacher addressed the class as a whole. Transcripts were created from the audio files. The transcripts were coded for the different purposes of verbal support being offered by the teachers.

Additionally, transcripts provided context for the learning activities in which the support was taking place. An initial set of a priori codes were established based on prior research (Krajcik et al., 2000) and were refined and subdivided based on observations of patterns within the classroom dialogue (Miles, Huberman, \& Saldaña, 2014). This process gave rise to three coding levels and an initial codebook. Three researchers individually coded each turn of talk with one or more codes for each level. A turn of talk was defined as a block of sentences with one speaker, beginning and ending with either another person speaking or a long pause. After coding 5\%, three coders discussed disagreements until they reached consensus, and refined the codebook to apply the new set of code definitions for the next $5 \%$. This was repeated until percent agreement was $80 \%$ or greater for $20 \%$ of the transcripts. After agreement was reached, two coders coded the remaining transcripts using the final codebook. For any turns of talk that coders were uncertain about coding, the first coder indicated their uncertainty. In all such cases, their coding was discussed with and confirmed by the second coder.

We chose to code turns of talk rather than sentence by sentence because the purpose of teacher talk often progressively built throughout a turn of talk, rather than being achieved through a single sentence. A single code could then be applied to a turn of talk with either one or multiple examples of that code. Turns of talk could also contain examples that lead to the application of multiple codes. For these reasons, we chose to report percentages of teacher talk for each purpose, rather than the counts. Representations were created to show differences in percentages 
of codes across sections and lessons. Examples of the codes were selected to highlight differences.

\section{Teacher talk codes}

The transcripts show whether the teacher or students were talking, which we separated into student talk or teacher talk for each turn of talk. In this analysis, we focused on teacher talk. First, teacher turns of talk were coded as either support or not support (Level 1; Table 2). Support involved the teacher making verbal changes to the activity or clarifying key concepts to support students' engagement with the material and sensemaking of the science practices in a way that they may not do on their own. Not support involved behavioral or logistical comments.

Table 2. Codes Applied to Teacher Talk and Definitions.

\begin{tabular}{|c|c|c|c|}
\hline Level 1 & Level 2 & Level 3 & Definition \\
\hline \multirow{6}{*}{ Support } & \multirow{2}{*}{$\begin{array}{l}\text { practice-based } \\
\text { Epistemic }\end{array}$} & Global & $\begin{array}{l}\text { Explicitly explains how practices fit within the } \\
\text { larger process of engineering }\end{array}$ \\
\hline & & Classroom & $\begin{array}{l}\text { Explicitly explains how an activity fits into the } \\
\text { larger project or orients students to the project }\end{array}$ \\
\hline & \multirow{3}{*}{$\begin{array}{l}\text { practice-based } \\
\text { Practical }\end{array}$} & Sensemaking & $\begin{array}{l}\text { Supports students to make sense of new } \\
\text { information or build new understandings }\end{array}$ \\
\hline & & $\begin{array}{c}\text { Engaging Prior } \\
\text { Knowledge }\end{array}$ & $\begin{array}{l}\text { Elicits relevant student ideas to engage their } \\
\text { prior knowledge }\end{array}$ \\
\hline & & Doing & $\begin{array}{l}\text { Models how to do a particular practice, generally } \\
\text { in the form of instructions or a demonstration }\end{array}$ \\
\hline & $\begin{array}{l}\text { Not Practice- } \\
\text { Based }\end{array}$ & & $\begin{array}{l}\text { Supports students but not towards a specific } \\
\text { practice }\end{array}$ \\
\hline Not Support & & & $\begin{array}{l}\text { Focuses on facilitating movement in the } \\
\text { classroom, calling on students, or managing } \\
\text { behavior }\end{array}$ \\
\hline
\end{tabular}

Next, turns of talk coded as support were broken into sub-codes (Level 2) of practice-based or not practice-based. The practice-based turns of talk were then coded for the specific engineering practice such as defining problems, generating solutions, testing and evaluating designs, or refining and communicating designs. If a turn of talk did not support students toward a specific engineering practice, the turn of talk was coded as not practice-based. Examples of not practicebased included support given to students to help them to answer a teacher question that was too broad or prompts to extend the group conversation (e.g., "what do you think?).

The practice-based turns of talk were also coded for practice-based epistemic and practice-based practical support. If the turn of talk explicitly supported students to make connections to the broader purpose of the work within an engineering practice, then it was coded as epistemic. If a turn of talk supported students to understand the activities of the lesson or how to engage in 
those activities related to an engineering practice, it was coded as practical. Some turns of talk were coded as both epistemic and practical if they contained elements of both, leading to percentages of greater than 100 in certain categories below.

Finally, epistemic teacher talk was divided into Level 3 codes of global and classroom. Global support involved teacher talk that provided information about how the practice fit within the larger process of science or engineering. Classroom support involved teacher talk that explicitly addressed how an activity fit into the larger project or oriented students to the classroom project. Practical teacher talk was divided into Level 3 codes of sensemaking, engaging prior knowledge, and doing. Sensemaking was used for teacher talk that helped students make sense of new information by building new understandings from that information. Engaging prior knowledge was teacher talk that reminded students about practice-based information that the students already knew that would be applicable to the project. Doing involved teacher talk that gave instructions or demonstrations about how to do a particular practice. Each turn of talk could have multiple Level 3 codes for each category of epistemic and practical.

\section{Findings}

To answer how and to what extent upper-elementary teachers verbally supported students' engagement with engineering practices for different student groups, we describe patterns of talk within whole class discussions and the support for engineering practices across the lessons. We then present the proportion of each code that occurred in each of the two class sections and highlight exemplars of the codes to illustrate the different purposes of verbal support.

Overall, for both classes, the percentage of student talk (Orange Class: 18\%; Blue Class: 15\%) was lower than the percentage of teacher talk (Orange Class: 82\%; Blue Class: 85\%) during whole class discussions. This finding indicates that whole class discussions were similarly teacher-centered for these lessons in both sections.

\section{Patterns of talk}

Across the lessons, we observed differences between the class sections in the ways that teachers structured their support within whole class discussions. In a side-by-side comparison of the transcripts of the two class sections, the Orange Class had more back-and-forth discussions between the teachers and the students while the Blue Class had more extended instances of teacher talk without students engaging in the discussion. For example, the Orange Class had an overall higher level of not practiced-based support (Orange Class: 27\%; Blue Class: 16\%). However, this support typically was in the form of encouraging further student participation in class discussion. Teachers would ask, for example, "What else do you want to add?" or other participation-prompting questions that often furthered the discussion in an open nature for the Orange Class.

Further, we also see differences in the distribution of teacher talk throughout the duration of the lessons. In the Orange Class, students typically worked on activities with teachers intermittently providing help or feedback. In the Blue Class, teachers appeared to anticipate student challenges by proactively offering verbal supports before students began working on activities such that students had a brief work session only at the end of the lesson. An example comes from the Communicate lesson where students in both classes had opportunities to refine their designs and 
choose designs to present. When students in the Orange Class were working, the teachers gave intermittent verbal support based on student progress in five separate occurrences. For each instance of support, teachers addressed the whole class to help them with both refining and preparing their presentations, such as, "Don't forget to change your hourly rainfall to 1 inch. I see a lot of people with really low numbers," or "You might want to include a sentence or two about each one of the designs you came up with." After each statement, students were then allowed to return to work.

In the Blue Class, the teachers spent a large portion of the class reviewing the same points as they had with the Orange Class. However, they reviewed all of these points before students began working. While students worked, teachers did not offer any whole-class verbal support. For example, one teacher addressed the class at the end of the of the lesson,

Teacher: Okay guys, you should be at a place where you can take screenshots, hopefully. If you haven't done screenshots of your designs, and you don't know how to do that, please let us know. Great. How many people have 2 designs that they have tested and that they are willing to submit, or make part of their presentation? How many people have 3 designs? Okay. So we're done testing. Everybody say done testing.

Students: Done testing.

\section{Support for engineering practices}

For each of the lessons, we consider the focus and corresponding engineering practices in which we expected to see teachers supporting student engagement compared to the engineering practices in which teacher talk actually supported student engagement (Table 3).

Table 3. Engineering practices supported by teacher talk by lesson and class.

Engineering practices Orange Class Blue Class

Design Lesson

Generating solutions

Problem definition

Test Lesson

Testing and evaluating designs

Problem definition

Communicate Lesson

Refining designs

Problem definition

Communicating designs

$\begin{array}{ll}31 \% & 52 \% \\ 69 \% & 46 \%\end{array}$

$46 \%$
$100 \% \quad 29 \%$

$0 \% \quad 71 \%$

Note: Italicized practices are the focal practices of the lesson. 
We found that each class section received a similar proportion of teacher talk that supported engineering practices in the Design lesson (Orange Class: 70\%; Blue Class: 68\%) and the Test lesson (Orange Class: 77\%; Blue Class: 77\%) with a relatively larger proportion of practicedbased support offered in the Test lesson. In the Communicate lesson, there was a greater percentage of teacher talk supporting engineering practices in the Orange Class $(96 \%)$ than in the Blue Class (65\%).

When examining teacher talk in the Design lesson, we expected to see teachers primarily supporting students in designing solutions for their water run-off problem. However, a large part of the teacher talk (Orange Class: 69\%; Blue Class: 46\%) was spent reminding students of the project parameters set forth by the curriculum which indicates teachers' efforts to support students to consider project constraints when defining the problem. The remainder of teacher talk (Orange Class: 31\%; Blue Class: 52\%) supported students to create their design prototypes on paper which indicates efforts to support students in designing solutions.

Similarly, in the Test lesson, we expected teachers to support students primarily to test and evaluate their designs using the computational models that they built in a previous lesson. In the Orange Class, teachers briefly referred back to computer models and then let students test their designs with their own computer models. As a result, $100 \%$ of teacher talk in the Orange Class supported testing and evaluating designs. In the Blue Class, teachers gave additional support in understanding the project goals by reviewing project parameters through defining the problem (71\%). As a result, $29 \%$ of teacher talk in the Blue Class supported testing and evaluating designs.

Finally, in the Communicate lesson, we expected a majority of teacher talk to be focused on supporting students in refining their initial designs and communicating their final designs through a presentation. In the Orange class, teacher talk primarily supported communicating final designs (61\%). Additionally, teacher talk supported students to define problems (39\%), so that students could include the problem definition within their presentation. In the Blue Class, teacher talk was less focused on the communication of their final designs $(50 \%)$ and defining problems $(21 \%)$ as students also needed additional support to refine their designs $(29 \%)$.

\section{Epistemic, practical, and not practice-based teacher talk}

Epistemic, practical, and not practice-based teacher talk is shown in Table 4. Comparing the purposes of the support broadly, the majority of teacher support was practical, rather than epistemic, across all three lessons. Teachers focused their support on helping students engage practically with the lessons, as the curriculum contained complex activities (e.g., using computational models to test designs). Examples of this included teachers explaining how to use students' computational models to test their designs or guiding students to reflect on their prior knowledge to consider how certain materials may or may not be accessible to students with physical disabilities. 
Table 4. Epistemic, practical, or not practice-based teacher talk by class.

\begin{tabular}{lcccccc}
\multirow{2}{*}{ Lesson } & \multicolumn{2}{c}{ Epistemic } & \multicolumn{2}{c}{ Practical } & \multicolumn{2}{c}{ Not Practice-Based } \\
\cline { 2 - 7 } & Orange & Blue & Orange & Blue & Orange & Blue \\
\hline All Lessons & $7 \%$ & $17 \%+$ & $66 \%$ & $67 \%$ & $\mathbf{2 7 \% +}$ & $16 \%$ \\
Design & $6 \%$ & $15 \%+$ & $66 \%$ & $75 \%+$ & $\mathbf{2 8 \%}{ }^{+}$ & $10 \%$ \\
Test & $0 \%$ & $11 \%+$ & $82 \%$ & $79 \%$ & $\mathbf{1 8 \%} \%^{+}$ & $11 \%$ \\
Communicate & $12 \%$ & $23 \%+$ & $\mathbf{5 6 \%} \%^{+}$ & $50 \%$ & $32 \%$ & $28 \%$ \\
\hline
\end{tabular}

Note: + Indicates Class with percentage difference of $5 \%$ or more; bolded when the Orange Class and italicized when the Blue Class. Talk could be double coded for epistemic and practical, so some class sections sum to $>100 \%$.

Comparing the class sections, there was a greater proportion of epistemic support in teacher talk for the Blue Class across each of the three lessons. Teachers focused on framing the lessons for the Blue Class within a greater context but did not for the Orange Class. For example, in the Test lesson much of the teacher talk in the Blue Class was concerned with setting the stage for the project. The teacher introduced the class by saying "I just wanted to orient you to what we're doing today." Following this, the teacher spent the majority of the discussion giving students context for the lesson within the broader project by reviewing all of the project constraints and vocabulary words with the whole class. The teacher went into detail by asking questions such as "what does minimize mean?" In contrast, the teacher started the Test lesson for the Orange Class by saying "All right, so ladies and gentlemen, we're going to pick up exactly where we left off." Instead of asking questions about the criteria, the teacher summarized the criteria in a brief sentence before quickly moving into providing practical support for their activities for the day. The teacher then responded to student questions while they were working.

\section{Types of epistemic talk}

A summary of the different types of epistemic support is shown in Table 5. The majority of epistemic teacher talk in both classes was focused on relating the current lesson to the larger project, classroom epistemic support. In some cases, the percentage of teacher talk dedicated to each of these purposes differed significantly, which we defined as $5 \%$ or more, between the two class sections. We provide examples to illustrate some of these significant differences.

Table 5. Types of epistemic teacher talk

\begin{tabular}{lcccc}
\hline & \multicolumn{2}{c}{ Global } & \multicolumn{2}{c}{ Classroom } \\
\cline { 2 - 5 } & Orange & Blue & Orange & Blue \\
\hline Overall & $29 \%$ & $25 \%$ & $71 \%$ & $75 \%$ \\
Design & $33 \%$ & $38 \%+$ & $67 \%$ & $63 \%$ \\
Test & $\mathrm{n} / \mathrm{a}$ & $0 \%$ & $\mathrm{n} / \mathrm{a}$ & $100 \%$ \\
Communicate & $\mathbf{2 5 \% +}$ & $20 \%$ & $75 \%$ & $80 \%+$ \\
\hline
\end{tabular}

Note: + Indicates Class with percentage difference of $5 \%$ or more; bolded when the Orange Class and italicized when the Blue Class. No observations of Global Epistemic in the Orange Class in the Test lesson. 
Most of the epistemic support was oriented to the project (classroom; Table 5). For example, in the Communicate lesson teacher reminded the Blue Class of how their project will be evaluated by the principal based on the project constraints, "When [the principal] talked about this challenge, which one do you think he's going to care about the most? Is he going to care that you got it within budget or is he going to care that you got the runoff as low as possible?" This relates the immediate activity to the larger purpose of the classroom project.

There were fewer examples of teachers connecting to engineering more broadly (global; Table 5). For example, one teacher stated in the Communicate lesson for the Orange Class, "And this is really what engineers do, is they form science experiments first and then they figure out how to design a solution in many cases." This connects the immediate activity to broader notions of what engineers do. Other discussions of epistemic global ideas had more depth, but these were less common. An example of global epistemic support with more depth occurred in the Design lesson for the Orange Class:

We have the ability to make models of models and we can do that using the technology that makes virtually everything. Basically just using computers, using computer models. So nowadays when we really want to make especially expensive things, but really anything we develop a computer model to make it. I'll give you an example. A really good example is cars or airplanes or big expensive pieces of equipment. Imagine if every design they thought about, they had to create out of metal pieces, how expensive that would be to test it, to refine it, to make it better. It would be extraordinarily expensive to do that. So instead of doing that, we make a computer model and we use data that they've collected, maybe from actually crashing cars and to see how safe they are for example, or um, maybe data from people, you know, riding in certain types of cars to see how comfortable they would be. And so we actually have done science experiments on cars and so we can get some data from that and then put it into our computer models. We've done science experiments on runoff, that we can put into our computer model.

These examples illustrate how teachers orient students to their classroom project as well as the larger process of engineering.

\section{Types of practical talk}

A summary of the different types of practical support is shown in Table 6. For practical teacher talk, the data show that overall, the teachers supported students through sensemaking, engaging prior knowledge, and doing in similar proportions across the sections. Again, the percentage of teacher talk dedicated to each of these purposes sometimes differed significantly between the two class sections. We provide examples to illustrate some of these significant differences. 
Table 6. Types of Practical Teacher Talk

\begin{tabular}{lcccccc}
\hline & \multicolumn{2}{c}{ Sensemaking } & \multicolumn{2}{c}{$\begin{array}{c}\text { Engaging Prior } \\
\text { Knowledge }\end{array}$} \\
\cline { 2 - 7 } & Orange & Blue & Orange & Blue & Orange & Blue \\
\hline Overall & $25 \%$ & $33 \%+$ & $\mathbf{3 4 \%}+$ & $29 \%$ & $41 \%$ & $39 \%$ \\
Design & $36 \%$ & $39 \%$ & $\mathbf{3 6 \%}+$ & $27 \%$ & $28 \%$ & $34 \%+$ \\
Test & $\mathbf{2 7 \% +}$ & $18 \%$ & $13 \%$ & $59 \%+$ & $\mathbf{6 0 \%} \%$ & $24 \%$ \\
Communicate & $6 \%$ & $32 \%+$ & $\mathbf{5 0 \%} \%$ & $9 \%$ & $44 \%$ & $59 \%+$ \\
\hline
\end{tabular}

Note: + Indicates Class with percentage difference of $5 \%$ or more; bolded when the Orange Class and italicized when the Blue Class.

In addition to different proportions of the types of practical support in each lesson, the proportion of these types of practical support also differed between the class sections. For the Orange Class, teachers heavily engaged students' prior knowledge in the Design and Communicate lessons. In the Design lesson, teachers mainly tried to elicit students' prior knowledge about the project constraints so that students could account for these constraints within their design solutions. Similarly in the Communicate lesson, teachers focused on reminding students of these same project constraints so that students could appropriately include these constraints when presenting their designs. For example, one teacher told students:

You need to make sure your presentation includes all of those, the costs, run off, the number of accessible squares and the screenshots ... so that when you guys are giving your presentations, you know, you could explain what caused runoff and why you decided to change from that design, because we need to know. Tomorrow, not only are you going to be presenting your final, but you need to explain why you decided to go with that design.

In the Blue Class, teachers did not try to engage students' prior knowledge as often as they did in the Orange Class (Table 6). Instead, in the Design and Communicate lessons teachers spent a larger proportion of teacher talk supporting students to do the activities by breaking down the provided task into smaller steps. Specifically in the Communicate lesson, instead of focusing on the project constraints, the emphasis for the Blue Class was on how to create their presentation:

And if you don't know how to take a screenshot, we can help you with that. But you should have at least two designs and then when you're ready to start with your presentation, let [us] know and we can tell you where the presentation is found ... You're going to take screenshots of your designs that you are going to go to google classroom, presentation, and I'm actually going to ask you to make a copy, okay? So you're going to press 'make a copy', and then the slide show should pop up.

Thus, students in the Orange Class received support on what to include in their presentation while the Blue Class received support on how to make a presentation.

In the Test lesson, teachers supported students in the two class sections differently toward the use of computer models. Teachers primarily supported students in the Orange Class to test their 
designs with their computer models. For example, one teacher gave students specific troubleshooting support for how to use their computational model:

As you are testing your designs, some of you might be running into an issue where you're getting negative runoff. If you're getting negative runoff, that's because you need to reset where you test. So, down at the bottom, bottom of the code. So way below the absorption ratios for different materials, it says... there's a reset button here. If you press resets, it resets your uh rain gauges at the bottom .... If you want to run the same tests on the same design, you press this.

For the Blue Class, teachers did not give whole class trouble-shooting support. Instead the teacher focused whole class discussion on eliciting students' prior knowledge in the form of project constraints. For example, during the lesson, the teacher instructed students to go back to their notes:

So look at the very top of this one more time and let's remember the constraints from the very beginning. Can you, can I get, can I get a hand from people who have the ability to read those things at the top? We're gonna just jot it down really quickly up here, and then you're going to get a chance to test them. Yeah. What's one thing that your design should do? This is going again back to the very beginning.

The teacher then focused on discussing all of the constraints with students again in detail, "Your first designs right there on that page. What were the other, what were the other constraints? What were the other constraints besides stay in budget and stay within these class-defined parameters?" Thus, the emphasis in the Blue Class was on testing their designs and adhering to project criteria as opposed to specific whole-class support for using the computational models.

These examples illustrate how teachers used different types of practical support between the two class sections for the same lessons. Students in the two class sections then experienced support in the same lesson differently.

\section{Discussion}

Overall, there was a greater amount of teacher talk than student talk across both classes. Although this paper does not directly address the balance of teacher talk to student talk, results suggest that teachers may need support to lead more student-centered discussions about engineering practices. Results also demonstrate that teacher talk was largely practice-based across the three lessons and both classes. Additionally, there was a greater proportion of practical support than epistemic support across the lessons.

While we expected that teachers would have different purposes for their verbal supports in different lessons, there were also differences in the proportions of the purposes of supports offered between the two class sections. Thus, students in the two class sections had different experiences with verbal support toward engaging in engineering practices. Across the three lessons (Table 4), teachers provided a larger proportion of epistemic talk to focus on framing the lessons within the context of the project in the Blue Class than they did in the Orange Class. For the Orange Class, teachers provided more opportunities for students to engage in discussion and 
do engineering. The teachers may have assumed that students in the Orange Class understood the context and could engage in activities more readily with less epistemic support.

Specifically for the Design and Communicate lessons, the teachers focused on engaging students' prior knowledge in the Orange Class as they may have expected students to have background knowledge of activities and the ability to follow the provided task instructions. In contrast, teachers may not have anticipated the same level of prior knowledge of students in the Blue Class. Instead, the teachers focused less on eliciting prior knowledge and spent a larger proportion of their talk supporting students in doing and sensemaking. In the Communicate lesson, the Orange Class also had more direct support to engage in engineering practices of communicating project constraints whereas the Blue Class learned how to create a presentation and did not have the same support to participate in the engineering practice of communicating.

When teachers prepared students in the Orange Class to engage in engineering practices that they expected to be unfamiliar to the students, such as working with computer models in the Test lesson, the teachers focused on supporting students in sensemaking and doing these practices. In contrast for the Blue Class, the teachers focused on eliciting prior knowledge of the project constraints instead of giving support toward gaining new understandings of unfamiliar engineering practices.

Based on patterns of the coded teacher talk and student talk throughout the lessons, there were no occurrences of intermittent verbal support during activities recorded for the Blue Class while students were working. Further, the only instances of whole-class discussion in which the teachers addressed the Blue Class about their work was to check in on their progress instead of offering whole-class support for the quality of their work. Whole-class support for the Blue Class was also front-loaded as teachers anticipated potential student needs. Thus, students in the Blue Class seemed to receive fewer opportunities to engage in whole-class discussions, fewer instances of whole-class support in response to their work, and less practice-based support that would enable them to transfer knowledge of the engineering practices to future work. This difference in quality of supports may decrease the opportunities for students to rigorously engage with the engineering practices (Anderson, 1985).

Although supports implemented through teacher talk in these lessons were intended to help students engage in engineering learning, the two class sections had different opportunities to engage with the curriculum. These opportunities were sometimes limited for the Blue Class, which had a large percentage of students with IEPs. Thus, teachers may need additional guidance in order to implement appropriate supports through teacher talk without reducing the rigor of activity or opportunity for students to discuss and sensemake. This guidance could come from the curriculum materials themselves, from professional learning workshops, or from instructional coaches who can observe teacher practice and provide formative feedback in real time.

Although teachers may have provided different learning experiences for students in the different classes, their support did help students to engage in engineering practices. Teachers reminded students of criteria in the Design lesson to help students create solutions that met project criteria. Teachers engaged students to think about how they defined the problem in the Test lesson to help students evaluate their designs with appropriate criteria, instead of haphazardly changing designs 
or only thinking about one variable. Thus, teachers' verbal supports can help students engage in engineering practices, and the ways in which teachers can equitably support diverse students in engineering should be studied further.

\section{Limitations}

In the unit, there were only three engineering lessons. These engineering lessons occurred over a smaller number of classes than intended by the curriculum developers because of time constraints. We focused only on teacher talk within whole-class discussions, and the discussions only occurred within a single science classroom across two sections. The narrow scope of the data correspondingly limits the transferability of the findings to other instructional contexts, but the data do provide insights into the ways that the teachers differently supported the two class sections in this context. This paper does not explore the support that teachers provided to individual students or how supports were received by students within the classroom. In addition, some of the differences that we observe between the two class sections could be related to the first and second teachings of the same material.

Since we did not collect data on student discourse or engagement, we were unable to examine how teacher discourse patterns may be meaningfully connected to student experiences. Future studies should investigate how teacher discourse patterns could be connected to student discourse and engagement in challenging tasks. Additionally, this study raises questions about how to support teachers in enacting effective discourse patterns, which is important for the field and should be addressed in future studies.

\section{Conclusions}

In this study, teachers verbally adapted an NGSS-aligned curriculum to meet the needs of students within their two leveled class sections. The purposes of teachers' talk often varied between the class sections depending on the instructional activity as teachers utilized a variety of supports toward students' engagement in different engineering practices. They connected daily activities to broader contexts, elicited prior knowledge, facilitated sensemaking, and gave direct instructions. As teachers utilize these different verbal supports to help students engage in the specific engineering practices of each lesson, there were differences in the proportion of supports implemented toward meeting the needs of students in the different class sections.

We recognize the challenge for teachers in adapting their instructional practices to address student needs toward student-centered, discussion-based learning approaches. As teachers work to implement integrated engineering activities across different class levels, they may need guidance on their teaching so that all students can equitably engage in engineering learning opportunities. The findings from this study have implications for how verbal instruction can support students to engage with engineering practices. In this case, the perceived differences in student populations based on successes and struggles in other disciplines and contexts meant that the students received different kinds of support to engage with the engineering practices. The results from this study can inform future research on the kinds of educative materials needed within engineering and other NGSS-based curricula as well as professional development for upper-elementary teachers to enact whole-class discussions focused on increasing students' ability to engage in engineering practices. 


\section{References}

Aranda, M. L., Lie, R., Guzey, S. S., Makarsu, M., Johnston, A., \& Moore, T. J. (2018). Examining teacher talk in an engineering design-based science curricular unit. Research in Science Education, 1-19.

Arastoopour, G., Chesler, N. C., \& Shaffer, D. W. (2014). Epistemic persistence: A simulationbased approach to increasing participation of women in engineering. Journal of Women and Minorities in Science and Engineering, 20(3).

Atman, C. J., Adams, R. S., Cardella, M. E., Turns, J., Mosborg, S., \& Saleem, J. (2007). Engineering design processes: A comparison of students and expert practitioners. Journal of engineering education, 96(4), 359-379.

Capobianco, B. M., Diefes-dux, H. A., Mena, I., \& Weller, J. (2011). What is an engineer? Implications of elementary school student conceptions for engineering education. Journal of Engineering Education, 100(2), 304-328.

Chiu, J.C., McElhaney, K.W., Zhang, N., Biswas, G., Fried, R., Basu, S., \& Alozie, N. (2019, April). A Principled Approach to NGSS-aligned Curriculum Development Integrating Science, Engineering, and Computation: A Pilot Study. Paper presented at the NARST Annual International Conference, Baltimore, MD.

Crismond, D. P., \& Adams, R. S. (2012). The informed design teaching and learning matrix. Journal of Engineering Education, 101(4), 738-797.

Ganesh, T. G., \& Schnittka, C. G. (2014). Engineering education in the middle grades. Engineering in pre-college settings: Synthesizing research, policy, and practices, 89-115.

Krajcik, J., Blumenfeld, P., Marx, R., \& Soloway, E. (2000). Instructional, Curricular, and Technological Supports for Inquiry in Science Classrooms. In J. A. Minstrell \& E. H. Van Zee (Eds.), Inquiring into inquiry: Learning and teaching in science (pp. 283-315). American Association for the Advancement of Science.

Lave, J., \& Wenger, E. (1991). Situated learning: Legitimate peripheral participation. Cambridge university press.

Lindsay, E., Munt, R., Rogers, H., Scott, D., \& Sullivan, K. (2008). Making students engineers. engineering education, 3(2), 28-36.

Luo, Y. (2015). Design fixation and cooperative learning in elementary engineering design project: A case study. International Electronic Journal of Elementary Education, 8(1), 133-146.

Miles, M. B., Huberman, A. M., \& Saldaña, J. (2014). Qualitative Data Analysis: A Methods Sourcebook. Sage Publications.

Moje, E. B. (1995). Talking about science: An interpretation of the effects of teacher talk in a high school science classroom. Journal of Research in Science Teaching, 32(4), 349-371.

Moore, T. J., Glancy, A. W., Tank, K. M., Kersten, J. A., Smith, K. A., \& Stohlmann, M. S. (2014). A framework for quality K-12 engineering education: Research and development. Journal of pre-college engineering education research (J-PEER), 4(1), 2.

Morgan, P. L., Farkas, G., Hillemeier, M. M., Maczuga, S. (2016). Science achievement gaps begin very early, persist, and are largely explained by modifiable factors. Educational Researcher, 45(1), 18-35.

National Research Council. (2012). Discipline-based education research: Understanding and improving learning in undergraduate science and education. Washington, DC: National Academies Press.

Pantoya, M. L., Aguirre-Munoz, Z., \& Hunt, E. M. (2015). Developing an Engineering Identity 
in Early Childhood. American Journal of Engineering Education, 6(2), 61-68.

Reiser, B. J., \& Tabak, I. (2014). Scaffolding. In R. K. Sawyer (Ed.), The Cambridge Handbook of The Learning Sciences (2nd ed., pp. 44-62). Cambridge University Press.

Songer, N. B. (2006). BioKIDS: An animated conversation on the development of curricular activity structures for inquiry science. In R. K. Sawyer (Ed.), The Cambridge Handbook of The Learning Sciences (pp. 355-371). Cambridge University Press.

Songer, N. B., Shah, A. M., \& Fick, S. (2013). Characterizing teachers' verbal scaffolds to guide elementary students' creation of scientific explanations. School Science and Mathematics, 113(7), 321-332.

Watkins, J., McCormick, M., Wendell, K. B., Spencer, K., Milto, E., Portsmore, M., \& Hammer, D. (2018). Data-based conjectures for supporting responsive teaching in engineering design with elementary teachers. Science Education, 102(3), 548-570.

Wendell, K. B., \& Lee, H.S. (2010). Elementary students' learning of materials science practies through instruction based on engineering design tasks. Journal of Science Education and Technology, 19(6), 580-601. 